\title{
Engineering Design Thinking and Making: Online Transdisciplinary Teaching and Learning in a Covid-19 Context
}

\author{
Jinge Huang, Wenjie Pan, Yao Liu, Xiaohan Wang, and Wei Liu ${ }^{(\bowtie)}$ \\ Faculty of Psychology, Beijing Normal University, \\ Beijing 100875, People's Republic of China \\ wei.1iu@bnu.edu.cn
}

\begin{abstract}
This paper introduces an engineering design thinking and making course that has been taught at Beijing Normal University since 2019. In its 2year journey and iterations, both teachers and students learn to dance with ambiguity, collaborate in teams, build to think, and make ideas real. They embrace engineering design thinking and making and experience the maker culture of the China-US young maker competition in this 16-week semesterlong course. This year because of the Covid-19, the innovative course changed to online teaching. The course focus on people's basic needs during the Covid19, including study, fitness, shopping, entertainments and long-distance relationships and communication with family members. Student teams collaborate online to solve the special challenges of Covid-19 in innovative ways and deliver functional proof-of-concept prototypes along with in-depth documenta-tion that not only captures the essence of designs but the learnings that led to the ideas.
\end{abstract}

Keywords: Transdisciplinary education - Online teaching $\cdot$ Covid-19 · Chinese context

\section{Introduction}

Entrepreneurship education is gaining momentum in today's world. In recent years, entrepreneurship education has become increasingly important in engineering education [4]. Interdisciplinary, as a transdisciplinary interaction method, has a positive influence on the knowledge, ability, and quality structure of teachers and students [1]. Carrying out interdisciplinary education in universities helps to optimize students' knowledge structure, cultivate innovation ability. Moreover, improve overall quality, which is an inevitable choice for training innovative talents [2]. The cultivation of college students should emancipate the mind and update ideas [3]. With the help of interdisciplinary education. It can effectively improve the quality of teaching, integrate superior majors, broaden the knowledge of students. Moreover, strengthen the improvement training of students' comprehensive ability. As an effective way to cultivate innovative thinking, design thinking is more and more carried out in the form of courses in colleges and universities. As a methodology, the characteristics of integrating creative thinking into action have made it more and more popular among

(C) The Editor(s) (if applicable) and The Author(s), under exclusive license to Springer Nature Switzerland AG 2020

E. Markopoulos et al. (Eds.): AHFE 2020, AISC 1218, pp. 159-166, 2020.

https://doi.org/10.1007/978-3-030-51626-0_19 
educators. Moreover, it has also exerted a significant influence on education in the 21st century [9]. In China, more and more colleges and universities offer courses related to Design Thinking. Applying this way of thinking to the cultivation of undergraduates [10]. Undergraduate students are in the stage of learning socialization. The learning of undergraduate higher education and the thinking mode they cultivate all affect their socialization process and life path. At present, the cultivation of undergraduates mainly focuses on professional training, and there are shortcomings in innovation and practice [11]. The introduction of the concept and method of Design Thinking in undergraduate education is conducive to the cultivation of students' innovative consciousness. And the promotion of students' all-round development.

Since the early spring of 2020, Chinese universities have been experiencing an unprecedented massive "migration" from traditional in-class, face-to-face education to online education [8]. The outbreak of novel coronavirus pneumonia has brought significant challenges to higher education in China. How to complete the teaching in the epidemic is a real problem in front of every teacher. In the field of education, there is also thinking about "Internet + Education". The large-scale distance online teaching activities have put forward new requirements for the platform operators - the education management of colleges and universities, also teachers, and students. The "Design Thinking" course focuses on the user, context, emotion, interaction, technology, and human factors, through practicing engineering design thinking and making. In this year, because of the Covid-19, the innovative course changed to online teaching. The course takes the most basic life needs of people during Covid-19 as project topics and encourages students to use design thinking as a method to solve practical problems around them to optimizes the life experience during the epidemic through innovative solutions.

\section{Related Work}

Highly innovative ideas are largely the result of the flexible use of interdisciplinary thinking models [7]. A study results show that the characteristics of the interdisciplinary study is the multidisciplinary focus on the integration of knowledge [18]. Critical thinking ability and metacognitive skills are also learning to improve the other subjects in the process of development [12]. At the same time, the team cooperation ability of students in the process of collaborative learning a workout [13]. Contact with other disciplines can guide students through the process of deep learning. Making the knowledge internalization and using critical thinking to promote a higher level of cognitive processing capacity [19]. So, it can extend their focus from a discipline to the development of multiple structures of knowledge, and continue the evolution of the knowledge structure [20]. To help build a strong collective identity within the team is also one of the advantages of developing interdisciplinary teaching [21]. Although such a link would end as the project ended [22]. However, for stimulating and developing interdisciplinary connections between this purpose, it is worth [27]. Over the past two decades, there has been a new understanding of how to teach online. Online teaching is no longer regarded as a way for students to review, but a more personalized learning scene [5]. Therefore, higher requirements are put forward for online teachers. Shift in 
higher education to online education at the same time, and teachers also need to turntable teaching way [26]. Such a request is not accepted by teachers at the beginning, and they think it is unnecessary [14-16]. According to a survey, the main reason why teachers object to online education is that they have many difficulties in technical operation. The process of preparing online teaching materials will not only consume much time but also lose the opportunity to interact with students. Hinder teaching activities [23-25]. Attitude toward the opposite of people thinks educators need to equip students with the teaching skills to share knowledge [17]. Teachers do not have to answer all students' questions. It is a good way to encourage students to help each other appropriately [28]. Some researchers also give suggestions on the problems that may arise in online teaching. Because of possible cheating, each student can confirm whether it is the student by tracking the user's location when logging into the system with his or her user name and password [29]. Besides, as a teaching form different from traditional education, students' satisfaction with the curriculum will also be one of the criteria to evaluate the quality of the curriculum [6]. A satisfactory attitude can lead to positive learning, attitude, experience, and results [30]. At the same time, teachers with rich teaching experience and high-quality online course resources can stimulate students' moods, enhance students' learning enthusiasm and learning effect [31].

\section{Settings}

The Co-making the Future China-US Young Maker Competition is an activity supporting the China-US high-level consultation on people-to-people social and cultural exchange. In this spring semester, the research team has mentored and worked with 40 student makers who work in teams of 8 on design briefs concerning study, fitness, shopping, entertainment, and relationships in the Covid-19 context. The undergraduate students participating in the course come from various majors, including 13 different majors such as geography, Chinese language, education, economics, and psychology. The course advocates "learning by doing". This course has three distinctive features: 1) Project-based learning. The course takes the most basic life needs of people during Covid-19 as project topics and encourages students to use design thinking as a method to solve practical problems around them to optimizes the life experience during the epidemic through innovative solutions. 2) Maker-style education. Unlike some traditional courses that separate theory and practice, this course uses the Maker Competition to help students get inspiration in practice and experience the role of design thinking in the creative process. 3) Cooperation in collaborative innovation. Through online communication and collaboration, students are encouraged to expand their ideas and jointly create new solutions. Due to the Covid-19, the course changed from the original offline teaching to online teaching, retaining the form of transdisciplinary teamwork. 


\section{Online Teaching and Procedure}

Empathy is the first stage of the course and also the first stage of the design thinking process. The overall background of the course project was introduced. Unlike the offline observation and interviews of previous courses, in this semester course, students need to use the scope of their own observations or personal experience to conduct scene-based observations to understand and empathize with users. The form of interviews has also become mainly online interviews. Students formulated inter-view outlines through online discussions and understanding target users through online interviews. After the interview, the students completed the production of affinity maps through the online collaboration platform like ZOOM.

After completing the empathy for users, the course enters the Define phase. In the Define stage, the researchers used Persona and User Journey Map to help students understand their users' needs and pain points, thereby defining what problems the team needed to solve. First, students need to complete Persona through group collaboration to form a unified understanding of users. In previous classrooms, researchers handed out paper toolkits to each group. The team members discussed face to face, formed a consensus on their Persona, and filled in the paper toolkit. In the online classroom scenario, the researchers distributed the electronic version to each group. The students marked and modified the toolkit pictures through the "whiteboard" function in the online video conferencing software. In the next section, students still need to complete the User Journey Map in groups. How to complete the User Journey Map in the online teaching situation is a new challenge for researchers. In previous courses, students thought highly of the paper toolkit of the User Journey Map, especially in the part of making the emotional curve. The students analyzed the users' behaviors and emotions by pasting emotion stickers. In this process, they experienced more fun and gained useful inspirations. Under this premise, the researchers developed the toolkit. In this toolkit, students can visualize the user's emotions by filling the cell color. The toolkit design received good feedback, so the researchers continued to use a similar format for the Ideate stage of teaching. In the Ideate stage, group cooperation becomes more necessary and closer. Students need to complete brainstorming, C-box, MoSCoW, design brief through cooperation. This requires a lot of discussion and communication among team members. Therefore, the researchers continue to use the form mentioned above for toolkit design. After three rounds of silent brainstorming, each team harvested many solutions that could solve users' pain points. In the scheme screening, the researchers used different color backgrounds to represent the different quadrants of C-box, and used the relative positions of the cells in the spreadsheet to help students compare and screen brainstorming schemes. After that, the students conducted a new round of brainstorming on product functions. General, in the stages of Define and Ideate, researchers used online collaborative spreadsheet formation to design toolkits and implement methods, and finally completed the teaching transfer from offline to online.

The multidisciplinary team has now completed the design stage, further understanding of the users through the creation of a persona, several brainstorming, and refinement of the design, multi-dimensional analysis to obtain the existing design brief. 
The next stage of prototyping and testing will focus on building and implementing student programs in a way that combines technology and online education. 1) Interactive logic map. Explore and design more appropriate ways of interacting in conjunction with the needs of the team's target users and other stakeholders, which is followed by a structured disassembly and analysis of the product functionality. In order to solve the problem of unsynchronized information, a logic map is created by implementing a collaborative website online to show product functions, and the visual interactive logic map is a great help in translating programming into specific product displays. 2) Arduino Connection. Arduino and Visual Programming can be used interchangeably. It perfectly addresses the inability of team members from multidisciplinary backgrounds to join a collaborative disengaged group atmosphere, allowing everyone to participate in the hardware design and production process. The online simulation modeling software breaks the limitation of time and space, a simple drag and drop function can add electronic components to the hardware circuit part, can complete the intelligent matching design. Team members can learn from the circuit diagrams and, if necessary, do the soldering and solid construction of the product themselves. 3) Visual programming. Combined with Arduino, visual programming solves the problem of multidisciplinary operators needs to spend much time learning programming languages. After the operator edits the program module, the system will automatically generate the code, write the specific action of the components, which can achieve more convenient hardware construction of the product. Online visual programming solves the problem of not being familiar with the programming language and not being able to find bugs. At the same time, the system can conduct actual programming of specific functions in time, avoiding illegal operations and unnecessarily repeated programming of components. 4) Business Canvas. The sub-sectional business model canvas toolkit, visually demonstrates how the team describes and evaluates the business model and product value of their product. Combined with the detailed presentations made by each team, the team analyze the needs of the target users and other stakeholders, design the corresponding business model, and choose the value proposition and services to be provided to the users. The business canvas has more sections and covers a broader range of business aspects, so in the toolkit, the small sections are aggregated, using a right-to-left research and discussion logic, to fill in and analyze specific modules. 5) Storyboard. After completing the above product design process, the storyboard will be used to create multiple forms of narrative about the product and user interaction, such as a realistic or cartoonish style. There are few online storyboard collaboration software platforms, so the members engage less. The members will use a narrative timeline or write a script to tell a complete and vivid story so that the viewer can empathize with why the product is needed and recognize the output of the team.

\section{Conclusion and Future Perspectives}

This study is an online multidisciplinary design thinking course in the Covid-19 context, so the students are guided to solve problems innovatively. The research process demonstrated the feasibility of designing thinking online education and also 
demonstrated the advantages and problems of online education. In the future research, the researchers will better identify and use more appropriate online platforms for online education on design thinking, encourage more multidisciplinary students to join the online course, take advantage of the different professional backgrounds of the team members, and apply design thinking to different fields to help others and society to have a better experience.

Acknowledgments. We would like to thank our teaching team, students, and the Fulbright Research Scholar Grant (ID: PS00284539).

\section{References}

1. Piotr, D.A., Michael. B.T.: Supporting multidisciplinary collaboration: requirements from novel HCI education. In: Proceedings of the SIGCHI Conference on Human Factors in Computing Systems, pp. 1073-1076. ACM Press (2007)

2. Ben, S., Philip, H.: A case study of an interaction design approach to pervasive healthcare. In: Proceedings of the 12th EAI International Conference on Pervasive Computing Technologies for Healthcare, pp. 23-244. ACM Press (2018)

3. Wang, J., Yan, Y., Zhang, L.: Research on the design principles for intelligent products. In: Proceedings of the International Conference on Human-Computer Interaction, pp. 351-367. Springer (2019)

4. Roy, N., Schlosser, F., Pasek, Z.: Stimulating entrepreneurial interest in engineers through an experiential and multidisciplinary course collaboration. Entrepr. Educ. Pedagogy 3(1), 14 40 (2020)

5. Gloria, A.M., Uttal, L.: Conceptual considerations in moving from face-to-face to online teaching. Int. J. E-Learn. 19(2), 139-159 (2020)

6. Hampton, D., Culp-Roche, A., Hensley, A., Wilson, J., Otts, J.A., Thaxton-Wiggins, A., Fruh, S., Moser, D.K.: Self-efficacy and satisfaction with teaching in online courses. Nurse Educ. (2020)

7. Baran, M.L., Jones, J.E.: Online teaching and learning in higher education settings: focus on team effectiveness. In: Enriching Collaboration and Communication in Online Learning Communities, pp. 137-158. IGI Global (2020)

8. Bao, W.: COVID-19 and online teaching in higher education: a case study of Peking University. Hum. Behav. Emerg. Technol. 2, 113-115 (2020)

9. Wrigley, C., Straker, K.: Design thinking pedagogy: the educational design ladder. Innovat. Educ. Teach. Int. 54(4), 374-385 (2017)

10. Bowler, L.: Creativity through "maker" experiences and design thinking in the education of librarians. Knowl. Quest 42(5), 58 (2014)

11. Brenner, W., Uebernickel, F., Abrell, T.: Design thinking as mindset, process, and toolbox. In: Design Thinking for Innovation, pp. 3-21 (2016)

12. He, J., Freeman, L.A.: Can we trust teaching evaluations when response rates are not high? In: Implications from a Monte Carlo simulation. Studies in Higher Education, pp. 1-15 (2020)

13. Gepp, A., Kumar, K.: How to improve teaching using blended learning. In: Theoretical and Practical Approaches to Innovation in Higher Education, pp. 80-90. IGI Global (2020) 
14. Gratz, E., Looney, L.: Faculty resistance to change: an examination of motivators and barriers to teaching online in higher education. Int. J. Online Pedagogy Course Des. (IJOPCD) 10(1), 1-14 (2020)

15. Tolman, S., Dunbar, M., Slone, K. B., Grimes, A., Trautman, C.A.: The transition from teaching F2F to online. In: Handbook of Research on Creating Meaningful Experiences in Online Courses, pp. 67-84. IGI Global (2020)

16. Moorhouse, B.L.: Adaptations to a face-to-face initial teacher education course 'forced' online due to the COVID-19 pandemic. J. Educ. Teach. 1-3 (2020)

17. Richardson, K.: Online tools with synchronous learning environments. In: Handbook of Research on Online Pedagogical Models for Mathematics Teacher Education, pp. 68-78. IGI Global (2020)

18. Cresswell-Yeager, T.J., Aucoin, J., Budenz, D.: A framework for student engagement: strategies for faculty teaching online. In: Handbook of Research on Creating Meaningful Experiences in Online Courses, pp. 153-171. IGI Global (2020)

19. Zhang, X.: Thoughts on large-scale long-distance web-based teaching in colleges and universities under novel coronavirus pneumonia epidemic: a case of Chengdu University. In: 4th International Conference on Culture, Education and Economic Development of Modern Society (ICCESE 2020), pp. 1222-1225. Atlantis Press (2020)

20. Dimitrov, N., Haque, A.: Intercultural teaching competence in the disciplines: teaching strategies for intercultural learning. In: Multicultural Instructional Design: Concepts, Methodologies, Tools, and Applications, pp. 332-355. IGI Global (2020)

21. Huang, L., Lan, L.: Research on MOOC's teaching method about the category of innovation and entrepreneurship courses. In: 5th International Conference on Economics, Management, Law and Education (EMLE 2019), pp. 1322-1325. Atlantis Press (2020)

22. Beltran, V., Decker, J.C., Matzaganian, M., Walker, N.T., Elzarka, S.: Strategies for meaningful collaboration in online environments. In: Enriching Collaboration and Communication in Online Learning Communities, pp. 1-18. IGI Global (2020)

23. McDougald, J.S.: Quality assurance: breaking through the online learning plateau. In: Handbook of Research on Creating Meaningful Experiences in Online Courses, pp. 101117. IGI Global (2020)

24. Sofat, R., Sharma, R.: A study on perception of academicians towards online education courses. Online J. Dist. Educ. e-Learn. 8(1), 1 (2020)

25. Ben-Chayim, A., Reychav, I., McHaney, R., Offir, B.: Mediating teacher for distance teaching and learning model: an exploration. Educ. Inf. Technol. 25(1), 105-140 (2020)

26. Themelis, C., Sime, J.A.: From video-conferencing to holoportation and haptics: how emerging technologies can enhance presence in online education?. In: Yu, S., Ally, M., Tsinakos, A. (eds.) Emerging Technologies and Pedagogies in the Curriculum, pp. 261-276. Springer, Singapore (2020)

27. Ebner, M., Schön, S., Braun, C.: More than a MOOC-seven learning and teaching scenarios to use MOOCs in Higher Education and Beyond. In: Yu, S., Ally, M., Tsinakos, A. (eds.) Emerging Technologies and Pedagogies in the Curriculum, pp. 75-87. Springer, Singapore (2020)

28. Nwabude, A.A., Ogwueleka, F.N., Irhebhude, M.: The use of virtual learning environment and the development of a customised framework/model for teaching and learning process in developing countries. Education 10(1), 1-12 (2020)

29. Anand, S.V., Anand, T.S.: Using technology to teach and teaching about technology: synergies for the digital age. In: Handbook of Research on the Efficacy of Training Programs and Systems in Medical Education, pp. 379-403. IGI Global (2020) 
30. Anderson, J., Bushey, H., Devlin, M.E., Gould, A.J.: Cultivating student engagement in a personalized online learning environment. In: Handbook of Research on Fostering Student Engagement With Instructional Technology in Higher Education, pp. 267-287. IGI Global (2020)

31. Lopez, A.E., Olan, E.L.: Critical practices for teaching and learning in global contexts: building bridges for action. In: Accessibility and Diversity in Education: Breakthroughs in Research and Practice, pp. 613-629. IGI Global (2020) 